\title{
ADDING VALUE TO THE MIDWIFERY CURRICULUM THROUGH \\ INTERNATIONALISATION AND PROMOTION OF GLOBAL MOBILITY
}

\begin{abstract}
Despite the obvious need of student midwives for being exposed to meaningful learning experiences which consider engagement in the wider context of international health care and the associated values/benefits, there is lack of information on how this is achieved within midwifery curricula nationally and internationally. This paper will review the work that has been undertaken at the University of Nottingham to ensure the midwifery curriculum is internationalised and global mobility is promoted to all midwifery students. The processes and strategies put in place to encourage students' mobility is discussed in regard to curriculum development, Erasmus+ programme, elective placements and short term ad hoc international opportunities. Thanks to the implemented strategies outlined in this paper, our Division of Midwifery has seen an increase of students undertaking an international placement from $5 \%$ in $2013 / 14$ to $18 \%$ in 2015/16. Moving forward, future works will aim at developing 'virtual mobility' projects and evaluating the Erasmus+ programme in conjunction with European partners.
\end{abstract}




\section{Key phrases}

- This paper will review the work that has been undertaken at the University of Nottingham to ensure the midwifery curriculum is internationalised and global mobility is promoted to all midwifery students.

- The undergraduate midwifery course is based on a spiral curriculum where globalisation and internationalisation are considered across all modules throughout the programme.

- Students are introduced to international opportunities at the recruitment stage and this is reinforced across the programme leading up to the period when mobility might occur. This appears to stimulate curiosity amongst the students so they look forward to the mobility opportunities as well as seeing the benefits it will have for their future midwifery careers.

- Mobility is encouraged in a number of different ways, including Erasmus+, elective placements and other ad hoc short term opportunities.

- Thanks to the implemented strategies outlined in this paper, our Division of Midwifery has seen an increase of students undertaking an international placement from $5 \%$ in academic year $2013 / 14$ to $10 \%$ in $2014 / 15$ and $18 \%$ in $2015 / 16$.

- Moving forward, future works will aim at developing 'virtual mobility' projects and evaluating the Erasmus+ programme in conjunction with European partners. 


\section{Introduction}

Midwifery practice needs to constantly adapt and respond to mutable social, cultural and political factors. Considering immigration patterns in England and Wales, the population has become more and more ethnically and culturally diverse over the past 60 years (Smith, 2013). Consequently, midwives are called to provide care for a range of diverse communities in a culturally sensitive manner (Nursing and Midwifery Council, 2015). Green et al. (2008) argue that healthcare professionals share common beliefs and underpinning values which go beyond individual countries' boundaries; in fact, whilst the roles and clinical practices may vary in different states, there is 'a constant in the idea of promoting health and contributing to the care of the public' (Green et al., 2008: 982).

In a panorama of constantly changing populations in terms of social, cultural, religious, and economical status and in the light of increased rates of immigrant women and families in England (Migration Watch UK, 2012), midwifery students should be encouraged to appreciate differing health care provision from a global perspective. Contemporary midwifery education therefore demands engagement in the wider context of international health care.

Evidence on nursing curricula suggest that by internationalising education, students have the opportunity to engage meaningfully and responsibly with other cultures so that cultural differences are experienced, reflected on, respected and understood; this ability is variously identified by authors as cultural competence, awareness or sensitivity (Greatex-White, 2008; Green et al., 2008; Law and Muir, 2006; Milne and Cowie, 2013; Scholes and Moore, 2000). Other positive outcomes of embedding internationalisation within 
healthcare curricula are increase in cognitive development (Zorn et al., 1995); personal and professional growth (Haloburdo and Thompson, 1998; Scholes and Moore, 2000); development of communication skills and tolerance of others (Lee, 2004); appreciation of different forms of healthcare delivery (Green et al., 2008) and promotion of mobile workforce (Milne and Cowie, 2013). Curriculum internationalisation does not offer values to students only; it may also have positive implications for academics, who are encouraged to participate in international debates, exchanges and collaborations within both education and research fields.

Despite the obvious need of student midwives for being exposed to meaningful learning experiences which consider engagement in the wider context of international health care and the associated values/benefits, there is lack of information on how this is achieved within midwifery curricula nationally and internationally. The implementation of strategies ensuring successful integration of cultural awareness and sensitivity within midwifery education are also unclear.

As internationalisation of midwifery curricula deserves far greater attention than is currently the case, this paper will review the work that has been undertaken at the University of Nottingham to ensure the midwifery curriculum is internationalised and global mobility is promoted to all midwifery students. The processes that were required to make these changes to the curriculum will be discussed as well as the challenges for students, academics and administrative staff alike. 


\section{Defining 'globalisation' and 'internationalisation'}

Although linked, globalisation and internationalisation are distinct concepts. Globalisation is defined as the standardisation of processes and systems within a global community (Hinchcliff, 2000) whilst internationalisation refers to the individual country or unit and values its interaction with other individual countries (Allen and Ogilvie, 2004). In other words, the term global considers a worldwide scope and focus while internationalisation relates to the diversity of cultures existing within individual countries, communities and institutions (Knight, 2003). For the purpose of our curriculum we have taken a hybrid definition of our own which considers globalisation as midwifery students being aware of the differences between countries and being able to develop skills related to cultural sensitivity (Greatex-White, 2008; Green et al., 2008; Law and Muir, 2006; Milne and Cowie, 2013; Scholes and Moore, 2000); this is facilitated by their opportunities to be 'mobile' and make connections with healthcare professionals worldwide whilst studying to become a midwife. Internationalisation is represented by how the midwifery curriculum has been developed for students to learn how midwifery can be planned, adapted and implemented in a range of UK maternity settings being mindful of different cultures and local needs.

\section{The internationalisation of the midwifery curriculum}

The University of Nottingham is known as a global university with campuses not just in the United Kingdom but also in China and Malaysia. The University's strategy is for internationalisation to be embedded across all activities 
conducted at the University. Additionally the University has a strategy to promote global mobility across all programmes with its aim being for $30 \%$ of all students by 2020 to complete an element of international mobility during their programme (University of Nottingham, 2015a; University of Nottingham, 2015b). The opportunities to be mobile should be accessible to all students who are able to benefit from it. At the time of publication of the Internationalisation Strategy Document in 2015 by the University International Office, the mobility across the University was 22\% (University of Nottingham, 2015b). However, the midwifery programme was starting at a much lower percentage at approximately only $5 \%$ in the academic year $2013 / 14$ of all midwifery students undertaking international placements.

In terms of national and international mobility, midwifery students within the Division had historically undertaken a two weeks' elective placement but the period was largely used to stay locally and return to placements where they felt they needed to most achieve their objectives. Additionally, just prior to reapproval there was only one Erasmus+ agreement so there were very limited opportunities for students across the cohorts to apply for the scheme.

The Division of Midwifery had the opportunity to review how internationalisation and global mobility would be articulated within the midwifery programme as a new curriculum was planned and developed for re-approval in 2015. This was first actioned by the appointment of Lead and Deputy Lead for Global Mobility as recognised roles within the Division. The new programme is based on a spiral curriculum (Bruner, 1960) where globalisation and internationalisation are considered across all modules throughout the programme (see Table 1. Map 
of modules content and learning objectives concerning globalisation and internationalisation).

\section{CONTENT}

- Introduction to maternity services and childbirth in other cultures;

- professional regulation of midwifery practice from both national and international perspectives;

- models of midwifery-led care from national and international perspectives;

- local, national and international policies related to the care of women with mental health;

- global perspectives of women's health needs;

- global citizenship;

- millennium development goals;

- midwifery models of care in the UK and internationally;

- [national and international] political drivers in maternity care and social policy;

- competency in a range of diverse antenatal, intrapartum and postnatal care taking into account physical, emotional, social, spiritual and cultural factors;

- the role of the midwife in contemporary society and the impact of globalisation;

- appreciation of midwifery practice within local, national and international settings.

\section{LEARNING OUTCOMES}

- Recognise the need to provide care reflecting the social determinants on childbearing women from national and international perspectives;

- recognise the role of the midwife in the promotion of normal birth from both a national and international context;

- apply current evidence to local and/or global aspects of midwifery practice;

- discuss the relationship between the politics of maternity care, sociological theory and the provision of high quality maternity services from international and national perspectives.

- assess the importance of clinical governance and risk management strategies including the EU working time directive;

- examine models of maternity care from local, national and international perspectives.

- critically analyse how [national and international] maternity policy influences women's ability to achieve normal childbirth;

- analyse the socio-political context of maternity care;

- recognise the importance of policy in the provision of midwifery care and the delivery of high quality maternity services and the effect this has on marginalise groups within society;

- critique research evidence from national and/or international sources;

- critically reflect on the ways in which the accountable and autonomous practitioner may develop their professional role to meet changing health care needs within a global community.

Table 1. Map of modules content and learning objectives concerning globalisation and internationalisation 
The key to the success of the Division's strategy is that students are introduced to international opportunities at the recruitment stage and this is reinforced across the programme leading up to the period when mobility might occur. This appears to stimulate curiosity amongst the students so they look forward to the mobility opportunities as well as seeing the benefits it will have for their future midwifery careers. Mobility is encouraged in a number of different ways, including Erasmus+, elective placements and other ad hoc short term opportunities.

Erasmus+ is a European Union training programme that enables exchange through mobility of higher education students by providing grants to cover additional expenses for them to study in another European university. The programme guarantees that the period that is spent in the host institution is recognised by the students' home university. The programme both enables learning abroad but also a time to live in another country and develop lifelong skills as a result. The Division decided to move to the Erasmus+ training scheme where partner organisations exchange students for two calendar months. It was felt that this was a more realistic time for students to be away from the Division without any disruption to their programme. The Division of Midwifery has had a partnership agreement with one partner for a number of years but this offered very limited opportunities for our cohorts due to the small number of students involved in the exchange. The Division has increased the number of partner institutions from one to four, including Malta, Italy, Ireland and Denmark. With a total of 10 places a year, $13 \%$ of each year's intakes have the opportunity through a competitive process to undertake an Erasmus+ placement. Students are selected using a number of criteria, including 
academic performance, a personal statement on how international placements will benefit their midwifery practice and a reference from their personal academic tutor. Student midwives are able to practice in the host institutions as they would do in the UK placements, supported by a trained mentor, so they continue to meet competencies in antenatal, intrapartum and postnatal care and record personally conducted births and other activities. However, on return from the Erasmus+ placement they do need to have their competencies verified by a sign off mentor according to the Nursing and Midwifery Council (NMC, 2008) requirements. Students who do not have the opportunity to go on an Erasmus+ placement will have the opportunity to learn about midwifery in other countries as they are given opportunities to engage with the incoming students both in theory and in practice.

The elective placement involves a two-week observational period in a national or international clinical setting chosen by the student occurring in the third year of the programme. Elective placements are aimed at encouraging students to widen perspectives of healthcare practice; help focus the mind and challenging assumptions; gain an understanding of midwifery practice outside usual placement areas; look at midwifery from a different angle and with new eyes; work within unfamiliar settings to encourage personal growth and professional development. A clear process for arranging elective placements has been implemented to encourage students to plan their elective in advance and ensure all steps, including a risk assessment, are completed on time. Each year the School of Health Sciences has an elective fair which enables student to be introduced to what opportunities are available as well as funding streams. 
Students also have other opportunities to consider the importance of internationalisation to their future careers. Funded attendance at local, national and international conferences is possible. Midwifery has also recently been included in the Universitas 21 group, the leading global network of research universities for the 21 st century. Other opportunities include student midwives from other universities coming to the University of Nottingham for short study tours. This enables all students to have the opportunity to meet students from across Europe to discuss, debate and exchange different midwifery practices.

\section{Mobility promotion strategies}

In order for students to apply for global mobility opportunities they need to be made aware of the opportunities available. Kent-Wilkinson et al. (2015) link an increase in awareness and information available to augmented students' openness to consider study abroad. The School not only seeks to inform students of the opportunities available but also uses mass communication to promote student mobility. In order to try and achieve effective communication the School currently uses a variety of student testimonials as part of its student mobility promotional strategy including student videos, sharing tips and recommendations using a system similar to Tripadviser and through the use of social media. Teng et al. (2015) describe social media as online word-of-mouth; in order to help stimulate online word of mouth promotion the School is currently running a photo competition using the School's Social Media pages to promote mobility by showcasing inspirational photographs from students. Mass communication allows the School to treat all students equally by providing the same information to all students at the same time; however, mass 
communication is often one-way communication making it difficult to assess how the message is being interpreted (Hundekar et al., 2009). Face-to-face communication between staff and students is also used to promote mobility. Two-way face-to-face communication provides an opportunity for questions to be asked and for staff to explain their message in more depth where necessary.

\section{Evaluation of internationalisation and mobility agenda}

The School evaluates its Erasmus+ programme by undertaking group feedback sessions with both visiting and returning students. The main aims of the feedback sessions are to recognise areas for improvement, identify what is working well and give students the opportunity to reflect on their experiences. Palermo (2013) acknowledges communicating openly about weaknesses can be extremely difficult. It is important that the School keeps an open mind when listening to students' feedback and does not fall into the trap of becoming defensive when receiving student feedback. Feedback is always logged in order to identify trends and provide an audit trail of how areas for improvement have been addressed. In line with other healthcare students' perspectives reported in the literature (Cowan, 2007; Green et al., 2008; Tuckett and Crompton, 2014), both our incoming and outgoing students have commented positively on their international placements, especially in regard to experiencing

a variety of maternity care services within a diverse cultural and social environment; aiding future career choices; facilitating personal and professional development. 


\section{Conclusions: moving forward...}

Thanks to the implemented strategies outlined in this paper, our Division of Midwifery has seen an increase of students undertaking an international placement from $5 \%$ in academic year $2013 / 14$ to $10 \%$ in $2014 / 15$ and $18 \%$ in 2015/16. Moving forward our focus will now be around sustaining the Erasmus+ exchanges as well as increasing the number of students who undertake an international elective placement. The Division's goal is to meet the University's global mobility target of $30 \%$ of all students having the opportunity to go abroad during their programme by the year 2020 (University of Nottingham, 2015b). Future work will aim at developing 'virtual mobility' so that students from different countries can engage in on-line activities on a midwifery topic of mutual interest. This widens the opportunities for students to engage with midwifery students in different countries and allows the participation to students who are unable to undertake an international placement for a range of reasons. We also propose to formally evaluate the experience and value of undertaking a midwifery Erasmus+ placement through a collaborative research project with our European partner organisations.

In terms of broader implications on clinical practice, the internationalisation of midwifery curricula is expected to encourage students from different backgrounds to develop cultural competence, awareness and sensitivity alongside the required skills of a qualified midwife (Greatex-White, 2008; Green et al., 2008; Law and Muir, 2006; Milne and Cowie, 2013; Scholes and Moore, 2000), contributing to the ultimate goal of offering compassionate and personalised family-centred maternity care services. 


\section{References}

Allen, M., Ogilvie, L. (2004) Internationalisation of higher education: potentials and pitfalls for nursing education. International Nursing Review: 51(2): 73-80.

Bruner, J. (1960) The Process of Education. A Landmark in Educational Theory. Cambridge MA: The President and Fellows of Harvard College.

Cowan, R.B. (2007) An appraisal of European exchange programmes for nursing students. Nursing Standards, 21(22): 40-47.

Greatex-White, S. (2008) Uncovering study abroad: Foreignness and its relevance to nurse education and cultural competence. Nurse Education Today, 28: 530-538.

Green, B.F., Johansson, I., Rosser, M., Tengnah, C., Segrott, J. (2008) Studying abroad: A multiple case study of nursing students' international experiences. Nurse Education Today, 28: 981-992.

Haloburdo, E., Thompson, M. (1998) A comparison of international learning experiences for baccalaureate nursing students: developed and developing countries. Journal of Nursing Education, 37(1): 13-21.

Hinchcliff, J. (2000) The globalisation of education. In: Paper Presented Crossroads of the New Millennium, Proceedings of the Technological Education and National Development Conference, April 8-10, UAE.

Hundekar, S.G., Appannaiah, H.R., and Reddy, P.N. (2009) Principles of Marketing. Mumbai: Himalaya Publishing House.

Kent-Wilkinson, A., Leurer, M.D., Luimes, J., Ferguson, L., Murray, L. (2015) 'Study abroad: Exploring factors influencing nursing students' decisions to apply for clinical placements in international settings'. Nurse Education Today, 35: 941-947.

Knight, J. (2003) Updating Definition of Internationalisation International Higher Education 2-3. 33 2-4.

Migration Watch UK (2012) The Impact of Immigration on Maternity Services in England. Available at https://www.migrationwatchuk.org/briefing-paper/266 [accessed 18/01/2017]. 
Milne, A., Cowie, J. (2013) Promoting culturally competent care: the Erasmus+ exchange programme. Nursing Standard, 27(30):42-46.

Law, K., Muir, N. (2006) The internationalisation of the nursing curriculum. Nurse Education in Practice, 6:149-155.

Lee, N (2004) The impact of international experience on student nurses' personal and professional development. International Nursing Review, 51(2): 113-122.

Nursing and Midwifery Council (2008) Standards to support, learning and assessment in Practice. London: Nursing and Midwifery Council.

Nursing and Midwifery Council (2015) The Code. Professional standards of practice and behavious for nurses and midwives. London: Nursing and Midwifery Council.

Palermo, J. (2013) 'Linking student evaluations to institutional goals: a change story'. Assessment \& Evaluation in Higher Education, 38(2): 211-223.

Scholes, J., Moore, D. (2000) Clinical exchange: one model to achieve culturally sensitive care. Nursing Inquiry, 7: 61-71.

Smith, C.W. (2013) 2011 Census analysis: Immigration Patterns of Non-UK Born Populations in England and Wales in 2011. Office for National Statistics.

Teng, S., Kong, K. W. and Chong, A. Y. L. (2015) 'Study abroad information in the new media'. Journal of Marketing for Higher Education, 25(2): 263-285.

University of Nottingham (2015a) Global Strategy 2020 [available from https:www.nottingham.ac.uk/about/uon-global-strategy-2020.pdf] (accessed 4/6/16).

University of Nottingham (2015b) Internationalisation Strategy Document. [available from www.nottingham.ac.uk/globaluniversity/index.aspx] (accessed 4/6/16).

Tuckett, A., Crompton, P. (2014) Qualitative understanding of an international learning experience: What Australian undergraduate nurses and midwives said about a Cambodia placement? International Journal of Nursing Practice, 20: 135-141. 
Zorn, C., Ponick, D., Peck, S. (1995) An analysis of the impact of participation in an international study program on the cognitive development of senior baccalaureate nursing students. Journal of Nursing education, 34(2): 67-70. 